Review Article

\title{
Mesenchymal Stem Cells as Therapeutic Agents and Novel Carriers for the Delivery of Candidate Genes in Acute Kidney Injury
}

\author{
Yuxiang Liu $\mathbb{D}^{1}$ and Jingai Fang $\mathbb{D}^{2}$ \\ ${ }^{1}$ Shanxi Medical University, No. 56, Xinjiannan Road, Taiyuan, 030001 Shanxi, China \\ ${ }^{2}$ First Hospital of Shanxi Medical University, No. 85, Jiefangnan Road, Taiyuan, 030001 Shanxi, China \\ Correspondence should be addressed to Jingai Fang; dr2017003@d.sxmu.edu.cn
}

Received 24 June 2020; Revised 6 October 2020; Accepted 27 November 2020; Published 11 December 2020

Academic Editor: Katia Mareschi

Copyright (C) 2020 Yuxiang Liu and Jingai Fang. This is an open access article distributed under the Creative Commons Attribution License, which permits unrestricted use, distribution, and reproduction in any medium, provided the original work is properly cited.

\begin{abstract}
Acute kidney injury (AKI) is a heterogeneous syndrome characterized by a dramatic increase in serum creatinine. Mild AKI may merely be confined to kidney damage and resolve within days; however, severe AKI commonly involves extrarenal organ dysfunction and is associated with high mortality. There is no specific pharmaceutical treatment currently available that can reverse the course of this disease. Notably, mesenchymal stem cells (MSCs) show great promise for the management of AKI by targeting multiple pathophysiological pathways to facilitate tubular epithelial cell repair. It has been well established that the unique characteristics of MSCs make them ideal vectors for gene therapy. Thus, genetic modification has been attempted to achieve improved therapeutic outcomes in the management of AKI by overexpressing trophic cytokines or facilitating MSC delivery to renal tissues. The present article provides a comprehensive review of genetic modification strategies targeted at optimizing the therapeutic potential of MSCs in AKI.
\end{abstract}

\section{Background}

Acute kidney injury (AKI) is a multifactorial syndrome characterized by a sharp decline in renal function and is associated with high morbidity and mortality. AKI can be triggered by a variety of predisposing factors, including sepsis, nephrotoxic drugs, and cardiac surgery. AKI affects an estimated $2 \%$ of hospital inpatients and more than $40 \%$ of critically ill patients [1]. Notably, the occurrence of AKI is steadily increasing in both developed and undeveloped nations. Despite decades of research providing deep insight into the pathogenesis of AKI, no specific options are available that can alleviate AKI or accelerate recovery; therefore, mainstay therapies remain supportive [2]. Particularly, patients who have survived AKI are at high risk for developing chronic kidney diseases and can even suffer serious health deteriorations following hospital discharge, imposing high socioeconomical burdens, particularly in low-income countries [3].
The pathophysiological mechanisms underlying AKI are complex and enigmatic [4]. Damage to the integrity of the endothelial barrier is initiating adhesion of leucocytes and platelets to the endothelium, which may be associated with microthrombi formation and microcirculatory dysfunction. Tubular epithelial cell injury has also been demonstrated to result in a rapid decline in microcirculatory function and glomerular filtration rate (GFR). Inflammatory response is crucial in mediating AKI due to both intrarenal and systemic inflammation considerably contribute to kidney injury [5]. Furthermore, it is becoming increasingly clear that the crosstalk between the immune system and kidney also plays a vital role in the development of AKI. B lymphocytes, T lymphocytes, macrophages, and dendritic cells all may be responsible for immune dysfunction after AKI. Notably, the antiinflammatory regulatory T cells and M2 macrophages exhibiting an intrinsic renal-protective effect by alleviating inflammation, facilitating tissue repair, and remodeling in AKI [6]. Additionally, accumulating evidence indicates that 


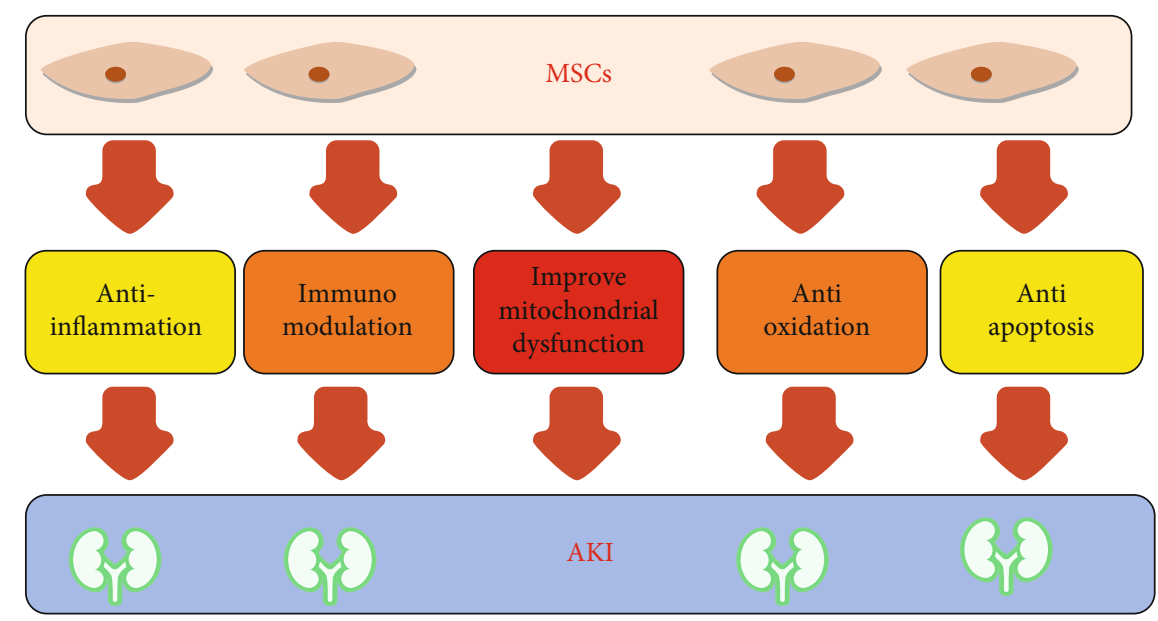

Figure 1: The mechanisms by which mesenchymal stem cells (MSCs) improve kidney injury.

mitochondrial damage is a driving factor in the progression of AKI by promoting the excess production of reactive oxygen species [7]. Pharmacological interventions aiming at one aspect of the mechanisms underlying AKI pathophysiology have failed to show beneficial effects. Thus, a novel therapeutic approach targeting multiple pathophysiological components of AKI is critically needed.

Mesenchymal stem cell (MSC) therapy is considered to have great therapeutic promise for managing AKI and has shown beneficial therapeutic effects in a variety of animal models of AKI. Kale et al. showed that MSCs infused after renal ischemia migrated specifically to injured regions and resulted in improvements in renal function [8]. Moreover, MSC transplantation improved impairments in renal function and attenuated proximal tubular epithelial cell injury, thereby facilitating recovery from AKI induced by cisplatin in a mouse model [9]. Additionally, systemically transplanted MSCs in a glycerol-induced mouse model of AKI localized to injured renal tissue and enhanced morphological and functional recovery [10].

\section{The General Characteristics and Identification of MSCs}

MSCs were first isolated from bone marrow by Friedenstein in the 1960s [11]. Subsequently, studies have shown that MSCs can be obtained from a variety of tissues, including adipose tissue, the placenta, amniotic fluid, and the umbilical cord blood [12]. For the uniform characterization of MSCs, the International Society for Cellular Therapy has developed a minimal set of criteria to define human MSCs [13]. First, MSCs should exhibit plastic-adherent characteristics when cultured in vitro. Second, MSCs must express CD90, CD73, and CD105 and cannot express CD11b, CD14, CD34, or CD45 as surface markers. Third, MSCs must possess the ability to differentiate into osteoblasts, chondrocytes, and adipocytes under appropriate induction conditions. Notably, accumulating evidence indicates that cellular surface markers and functionality are responsive to microenvironmental cues encountered in damaged tissues following MSC transplantation [14]. In addition, there are numerous researches have found that the therapeutic efficacy of MSC is primarily through paracrine mechanisms rather than cell differentiation [15].

\section{The Mechanisms of the Action of MSCs in AKI}

Increasing evidence has shown that the main mechanism of the action of MSCs in AKI is the paracrine secretion of bioactive molecules by MSCs rather than MSC transdifferentiation into renal-specific cells [16]. Interestingly, Bruno et al. demonstrated that MSC-derived microvesicles (MVs) stimulated the proliferation of tubular cells and increased the resistance of tubular cells to apoptosis by transferring a specific subset of cellular mRNAs, thereby accelerating functional and morphological recovery in glycerol-induced AKI [17]. In addition, mitochondrial dysfunction is increasingly recognized as a crucial contributor to the pathophysiology of AKI [18]. A study performed by Lee et al. suggested that MSC administration prevented injury to tubular epithelial cells by reversing mitochondrial dysfunction [19]. Accumulating evidence has demonstrated that renal-immune system crosstalk plays a vital role in the development and resolution of AKI, and inappropriate immune reactions are often observed in AKI [20]. Platelet-derived growth factor identified as one of important growth factors released from MSC is crucial for cell survival and proliferation in immune cells [21]. T cells, B cells, NK cells, neutrophils, and monocytes/macrophages are pivotal in mediating injury repair and renal recovery following AKI [22]. Semedo et al. demonstrated that MSCs attenuated ischemic AKI by shifting the inflammatory response towards a Th2 profile [23]. Furthermore, MSCs mitigated AKI induced by ischemia reperfusion through interactions with splenocytes, thereby increasing the percentage of regulatory $\mathrm{T}$ cells in the ischemic kidney [24]. M2 macrophages are crucial in attenuating inflammatory responses as well as stimulating tissue repair after kidney injury, and MSCs can reduce rhabdomyolysis-induced AKI by skewing macrophages towards an M2 phenotype [25]. The mechanisms by which MSCs improve kidney injury are illustrated in Figure 1. 


\section{Clinical Trials with MSCs for the Treatment of AKI}

In view of the promising results in different types of preclinical AKI models, several clinical trials have been performed to evaluate the safety and efficacy of MSC-based interventions for AKI patients. First, a phase 1 clinical trial was conducted to assess the safety and feasibility of allogeneic MSC administration to patients at high risk of AKI after openheart surgery [26]. Preliminary findings showed that postoperative administration of MSCs using a dose-escalation protocol was safe, as evidenced by the absence of serious adverse events or specific adverse events related to MSC infusion. Additionally, MSC therapy reduced both the length of hospital stay and the readmission rate by up to $40 \%$. Notably, none of the study participants treated with MSCs required renal replacement therapy, and all exhibited stable renal function, while nearly $20 \%$ of control patients developed AKI.

Moreover, Swaminathan et al. conducted a multicenter, randomized, double-blind, placebo-controlled phase 2 clinical trial to assess the safety and efficacy of allogeneic human MSC therapy for patients with AKI after cardiac surgery [27]. A total of 156 patients with AKI following cardiac surgery were enrolled in the study; 67 patients were assigned to receive intra-aortic MSCs, and 68 patients were assigned to receive the placebo. The findings revealed that no patients discontinued MSCs or placebo treatment due to serious adverse events during the study period. However, the researchers did not find significant differences between the two groups regarding the median time to recovery of kidney function, 30-day all-cause mortality, or dialysis. According to the recommendation made by the Data Monitoring Committee (DMC), the investigators stopped this clinical trial earlier than anticipated due to futility.

AKI is a multifactorial disease with high heterogeneity, which may mask the therapeutic effects of MSCs in certain subgroups of AKI patients. Therefore, additional large clinical trials in different types of AKI patients are urgently needed to shed light on the role of MSC therapy in the context of AKI. Several ongoing trials have been conducted to resolve these issues, and all registered trials on ClinicalTrials.gov regarding MSC therapy for patients with AKI are listed in Table 1.

\section{Genetic Modification Strategies to Improve the Therapeutic Potential of MSCs}

The latest findings add to a growing body of evidence that the paracrine, homing, immunomodulatory, anti-inflammatory, and tissue repair properties of MSCs can be strengthened through genetic modification [28]. It has been well established that the unique characteristics of MSCs make them ideal vectors for gene therapy $[29,30]$. Thus, there has been substantially increased interest in MSC-based genetic modification strategies in recent years. In recent decades, a variety of viral and nonviral gene delivery methods have been extensively studied and widely applied for the genetic engineering of MSCs.

\section{Viral Gene Delivery Methods}

Viral transduction is one of the most commonly used methods to deliver candidate genes to MSCs [31]. Viral vectors usually include lentiviruses, adenoviruses, and adenoassociated viruses (AVVs). Lentiviral-mediated gene delivery is a highly reproducible method with high transduction efficiency that results in long-term gene expression in MSCs. Traditionally, adenoviral vector application is limited due to its inherent disadvantages, such as the lack of integration and transient target gene expression. However, a modified adenoviral-mediated gene transduction strategy has been developed that can circumvent these disadvantages [32]. Moreover, AAVs are one of the leading viral-mediated gene delivery methods that can be used to import DNA sequences of interest into MSCs [33]. Although viral-mediated gene delivery techniques allow relatively stable transgene expression and high efficiency, their utilization remains challenging due to a variety of concerns, such as carcinogenicity, immunogenicity, toxicity, and high costs [34]. By performing a more detailed assessment of immune reactions to various viral vectors, intensive research to overcome the limitations associated with viral-mediated gene delivery methods will build a foundation for future clinical practices.

\section{Nonviral Gene Delivery Methods}

Nonviral gene transfer techniques commonly consist of physical and chemical methods [35]. Physical methods include microinjection, electroporation, and sonoporation. Microinjection is a relatively safe, inexpensive, and nontoxic method, but its application is limited because large micropipettes may result in marked cell damage. Electroporation is a highly reproducible method with the ability to transfer large genes, and the major concern with this technique is that the high voltage utilized in electroporation may contribute to cell damage [36]. Sonoporation is a promising gene delivery technique; however, MSCs transfected by sonoporation exhibit low gene transfer efficiency [37]. In addition to physical methods, a variety of chemical methods have been developed and used to deliver nucleic acid materials containing siRNA, mRNA, and DNA into MSCs via cationic lipids, cationic polymers, and inorganic nanoparticles [38]. Compared to those of viral transduction methods, the major disadvantages associated with nonviral gene delivery methods are transient transgene expression and relatively low gene transfer efficiency.

\section{Application of genetically modified MSCs in preclinical AKI models}

To achieve improved therapeutic outcomes in the management of AKI, genetic modification has been attempted to overexpress trophic cytokines or facilitate MSC delivery to renal tissues. A variety of target genes have been engineered for transfection into MSCs and applied in preclinical AKI models. These tested genes are summarized in Table 2. 
TABLE 1: Registered clinical trials involving the use of MSCs in AKI.

\begin{tabular}{|c|c|c|c|c|c|c|c|}
\hline $\begin{array}{l}\text { ClinicalTrials.gov } \\
\text { Identifier } \\
\end{array}$ & Study title & $\begin{array}{l}\text { Study } \\
\text { phase }\end{array}$ & $\begin{array}{c}\text { Actual/estimated } \\
\text { enrollment }\end{array}$ & $\begin{array}{c}\text { MSC } \\
\text { source }\end{array}$ & Primary outcome & Location & Status \\
\hline NCT04194671 & $\begin{array}{l}\text { Clinical Trial of Mesenchymal } \\
\text { Stem Cells in the Treatment of } \\
\text { Severe Acute Kidney Injury }\end{array}$ & $\begin{array}{l}\text { Phase } \\
1 / 2\end{array}$ & 80 participants & $\begin{array}{l}\text { Umbilical } \\
\text { cord }\end{array}$ & $\begin{array}{l}\text { Progression of } \\
\text { renal function } \\
\text { within } 28 \text { days } \\
\text { after receiving } \\
\text { MSC }\end{array}$ & China & $\begin{array}{l}\text { Not yet } \\
\text { recruiting }\end{array}$ \\
\hline NCT01275612 & $\begin{array}{l}\text { Mesenchymal Stem Cells in } \\
\text { Cisplatin-Induced Acute Renal } \\
\text { Failure in Patients with Solid } \\
\text { Organ Cancers }\end{array}$ & $\begin{array}{c}\text { Phase } \\
1\end{array}$ & 0 participants & $\begin{array}{l}\text { Bone } \\
\text { marrow }\end{array}$ & $\begin{array}{l}\text { The rate of renal } \\
\text { function loss up to } \\
15 \text { days } \\
\text { postcisplatin } \\
\text { infusion }\end{array}$ & Italy & Withdrawn \\
\hline NCT03015623 & $\begin{array}{l}\text { A Study of Cell Therapy for } \\
\text { Subjects with Acute Kidney Injury } \\
\text { Who are Receiving Continuous } \\
\text { Renal Replacement Therapy }\end{array}$ & $\begin{array}{c}\text { Phase } \\
1 / 2\end{array}$ & 24 participants & Unclear & $\begin{array}{l}\text { Outcomes out to } \\
\text { day } 28 \text { and serious } \\
\text { adverse events } \\
\text { through day } 180\end{array}$ & $\begin{array}{l}\text { United } \\
\text { States }\end{array}$ & Recruiting \\
\hline NCT01602328 & $\begin{array}{l}\text { A Study to Evaluate the Safety and } \\
\text { Efficacy of AC607 for the } \\
\text { Treatment of Kidney Injury in } \\
\text { Cardiac Surgery Subjects (ACT- } \\
\text { AKI) }\end{array}$ & $\begin{array}{c}\text { Phase } \\
2\end{array}$ & 156 participants & $\begin{array}{l}\text { Bone } \\
\text { marrow }\end{array}$ & $\begin{array}{l}\text { Time to kidney } \\
\text { recovery }\end{array}$ & $\begin{array}{l}\text { United } \\
\text { States }\end{array}$ & Terminated \\
\hline NCT00733876 & $\begin{array}{l}\text { Allogeneic Multipotent Stromal } \\
\text { Cell Treatment for Acute Kidney } \\
\text { Injury following Cardiac Surgery }\end{array}$ & $\begin{array}{c}\text { Phase } \\
1\end{array}$ & 15 participants & Unclear & $\begin{array}{l}\text { MSC-specific } \\
\text { adverse or serious } \\
\text { adverse events }\end{array}$ & $\begin{array}{l}\text { United } \\
\text { States }\end{array}$ & Completed \\
\hline NCT02563366 & $\begin{array}{c}\text { Effect of BM-MSCs on Early Graft } \\
\text { Function Recovery after DCD } \\
\text { Kidney Transplant }\end{array}$ & $\begin{array}{l}\text { Phase } \\
1 / 2\end{array}$ & 120 participants & $\begin{array}{l}\text { Bone } \\
\text { marrow }\end{array}$ & $\begin{array}{l}\text { Estimated } \\
\text { glomerular } \\
\text { filtration rate at } \\
\text { one month } \\
\text { posttransplant }\end{array}$ & China & Unknown \\
\hline NCT02561767 & $\begin{array}{l}\text { Effect of BM-MSCs in DCD } \\
\text { Kidney Transplantation }\end{array}$ & $\begin{array}{l}\text { Phase } \\
1 / 2\end{array}$ & 120 participants & $\begin{array}{l}\text { Bone } \\
\text { marrow }\end{array}$ & $\begin{array}{l}\text { Estimated } \\
\text { glomerular } \\
\text { filtration rate at } \\
\text { one month } \\
\text { posttransplant }\end{array}$ & China & Unknown \\
\hline
\end{tabular}

\section{CXC-Chemokine Receptor Type 4}

CXC-chemokine receptor type 4 (CXCR4) is the receptor for stromal cell-derived factor-1 (SDF-1), and the SDF1/CXCR4 axis has been shown to govern the migration of MSCs towards injured tissue in a variety of species and tissue types [39]. SDF-1 was shown to be significantly upregulated in response to ischemic conditions, including AKI. However, expression of CXCR4 was observed only in a small fraction of MSCs, and CXCR4 expression was significantly decreased during ex vivo expansion, which may result in the poor homing efficiency of transplanted MSCs to injured kidney tissues, thereby limiting their therapeutic potential. A variety of studies have focused on overexpressing CXCR4 to facilitate MSC mobilization [40]. Target overexpression of CXCR4 in MSCs was shown to significantly enhance the migration of MSCs to the injured kidney, as well as markedly reduce acute tubular necrosis scores and exert beneficial effects on renal function [41].

\section{Erythropoietin}

Erythropoietin, a hemopoietic growth factor secreted mainly by the kidney, is a pleiotropic cytokine with tissue-protective and reparative properties. Mounting evidence shows that erythropoietin is a vital modulator that is involved in a variety of biological processes, including cellular mitogenesis, maturation, survival, DNA repair, and angiogenesis [42]. In addition, erythropoietin is recognized to be a renotropic factor that supports tubular repair and accelerates renal functional recovery through erythropoietin receptors in the context of kidney injury [43]. The administration of exogenous erythropoietin to rats at the onset of AKI induced by bilateral renal artery occlusion exerted renoprotective effects by alleviating apoptosis, ameliorating renal dysfunction, and increasing tubular regenerative capacity [44]. Notably, MSCs overexpressing erythropoietin via retroviral transduction promoted renal epithelial cell survival, as measured by flow cytometry to assess annexin $\mathrm{V}$ and propidium iodide (PI) expression after cisplatin exposure in vitro [45]. Moreover, Epo-MSCs showed additional favorable effects on kidney function and survival in a mouse model of cisplatin-induced AKI [45].

\section{Kallikrein}

Tissue kallikrein, a critical member of the kinin-releasing enzyme family, is a serine protease expressed in many cell 
TABLE 2: Research regarding the application of gene-modified MSCs in preclinical AKI models.

\begin{tabular}{|c|c|c|c|c|c|}
\hline $\begin{array}{l}\text { Candidate } \\
\text { gene }\end{array}$ & AKI model & Vector & MSC source & Effects & Reference \\
\hline CXCR4 & Mice model of I/R AKI & $\begin{array}{l}\text { Lentiviral } \\
\text { vector }\end{array}$ & $\begin{array}{l}\text { Bone } \\
\text { marrow }\end{array}$ & $\begin{array}{l}\text { (i) Promote MSC paracrine actions in vitro } \\
\text { (ii) Accelerate migratory of MSCs to damaged } \\
\text { renal tissue } \\
\text { (ii) Improves treatment with BMSCs in I/R-AKI } \\
\text { mice }\end{array}$ & {$[41]$} \\
\hline EPO & $\begin{array}{l}\text { Mouse model of cisplatin- } \\
\text { induced AKI }\end{array}$ & $\begin{array}{l}\text { Retroviral } \\
\text { vector }\end{array}$ & $\begin{array}{l}\text { Bone } \\
\text { marrow }\end{array}$ & $\begin{array}{l}\text { (i) Improve survival of mouse kidney epithelial } \\
\text { cells in vitro } \\
\text { (ii) Enhance antiapoptotic and anti-inflammatory } \\
\text { effects } \\
\text { (iii) Improve survival of cisplatin-treated mice }\end{array}$ & {$[45]$} \\
\hline Kallikrein & Rat model of I/R AKI & $\begin{array}{l}\text { Adenoviral } \\
\text { vector }\end{array}$ & $\begin{array}{l}\text { Bone } \\
\text { marrow }\end{array}$ & $\begin{array}{l}\text { (i) Reduce inflammatory cell infiltration } \\
\text { (ii) Alleviate reactive oxygen species formation } \\
\text { (iii) Mitigate ischemia-induced renal injury }\end{array}$ & {$[49]$} \\
\hline VEGF & $\begin{array}{l}\text { Mice model of cisplatin- } \\
\text { induced AKI }\end{array}$ & $\begin{array}{l}\text { Adenoviral } \\
\text { vector }\end{array}$ & Embryo & $\begin{array}{l}\text { (i) Reduce renal cell apoptosis } \\
\text { (ii) Increase renal microvessel density } \\
\text { (iii) Reduce mortality of AKI mice }\end{array}$ & {$[54]$} \\
\hline HGF & Rat model of I/R AKI & $\begin{array}{l}\text { Adenoviral } \\
\text { vector }\end{array}$ & $\begin{array}{l}\text { Umbilical } \\
\text { cords }\end{array}$ & $\begin{array}{l}\text { (i) Promote the amelioration of renal function } \\
\text { (ii) Improve the proliferation of renal cells } \\
\text { (iii) Decrease apoptosis and inflammation }\end{array}$ & {$[60]$} \\
\hline Nrf2 & $\begin{array}{l}\text { Rat model of cisplatin-induced } \\
\text { AKI }\end{array}$ & $\begin{array}{l}\text { Adenoviral } \\
\text { vector }\end{array}$ & $\begin{array}{l}\text { Bone } \\
\text { marrow }\end{array}$ & $\begin{array}{l}\text { (i) Protect MSCs against cisplatin-induced } \\
\text { toxicities in vitro } \\
\text { (ii) Improve efficacy of MSCs against cisplatin- } \\
\text { induced toxicity }\end{array}$ & {$[64]$} \\
\hline Klotho & Mice model of I/R AKI & $\begin{array}{l}\text { Adenoviral } \\
\text { vector }\end{array}$ & $\begin{array}{l}\text { Bone } \\
\text { marrow }\end{array}$ & $\begin{array}{l}\text { (i) Improve antifibrotic effect in kidney } \\
\text { (ii) Mitigate the degree of renal histopathological } \\
\text { injury } \\
\text { (iii) Inhibit epithelial-mesenchymal transition }\end{array}$ & {$[69]$} \\
\hline $\mathrm{HO}-1$ & Rat model of I/R AKI & $\begin{array}{l}\text { Lentiviral } \\
\text { vector }\end{array}$ & $\begin{array}{l}\text { Bone } \\
\text { marrow }\end{array}$ & $\begin{array}{l}\text { (i) Promote anti-inflammatory effect of MSCs } \\
\text { in vitro } \\
\text { (ii) Protects BMSCs against apoptosis in vivo }\end{array}$ & {$[74]$} \\
\hline
\end{tabular}

types. Basic research has demonstrated that the kallikreinkinin system (KKS) is implicated in the physiopathological mechanisms of cardiovascular disease and the inflammatory response [46]. Notably, numerous studies have shown that kallikrein exerts nephroprotective effects in a range of disease models, including models of diabetes, postischemic heart failure, and acute cardiac ischemia [47]. Adenoviruses harboring the human kallikrein gene, when used for gene transfer, significantly decreased oxidative stress and TGF- $\beta$ expression, thereby attenuating salt-induced renal fibrosis, as identified by reduced collagen deposition and renal fibrosis scores [48]. Based on the above research, kallikrein may be a therapeutic target for ameliorating kidney injury. Intriguingly, MSCs genetically modified with the kallikrein gene were more effective in reducing inflammatory cell infiltration, decreasing reactive oxygen species formation, and mitigating ischemia-induced renal injury than unmodified MSCs due to the combination of MSC-mediated paracrine effects and the pleiotropic properties of kallikrein [49].

\section{Vascular Endothelial Growth Factor}

Vascular endothelial growth factor (VEGF) is a proangiogenic cytokine that initiates the proliferation and migration of endothelial cells, thereby contributing to the generation and stabilization of new blood vessels [50]. An integrated vascular network is critical for maintaining renal physiological functions, and studies have demonstrated that the inhibition of VEGF bioactivity is followed by podocyte injury and results in a defective renal structure [51]. VEGF is a principal paracrine cytokine that mediates renoprotective effects following AKI in the context of MSC therapy. The therapeutic potential of MSCs was decreased considerably after knockdown of VEGF via siRNA in a rat model of ischemic AKI $[52,53]$. Additionally, Yuan et al. investigated the effect of VEGF-modified human embryonic MSCs on cisplatininduced AKI in a nude mouse model [54]. In that study, cellular apoptosis, peritubular capillary density, renal function, and tubular structure were examined, and the results demonstrated that VEGF upregulation strengthened the renoprotective effect of MSCs in the context of these parameters [54].

\section{Hepatocyte Growth Factor}

Hepatocyte growth factor (HGF) is generated by cells of mesodermal origins and primarily acts on epithelial and endothelial cells to produce a wide range of biological effects, including the promotion of cellular growth, the stimulation 
of cellular motility, and the induction of tissue regeneration [55]. The circulating concentration of HGF is markedly increased following renal injury. Subcutaneous injection of HGF into rats markedly enhanced renal function recovery and tubular regeneration after AKI induced by bilateral renal artery occlusion [56]. Moreover, with the administration of recombinant human HGF in mice facilitated DNA synthesis in renal tubular cells and promoted remodeling of renal tissue after $\mathrm{HgCl} 2$-mediated renal injuries [57]. Evidence indicates that $\mathrm{HGF}$ acts in a renotropic manner to induce kidney regeneration after acute injury [58, 59]. Notably, Chen et al. established MSCs overexpressing HGF by using an adenoviral vector and then administered these MSCs into rats following ischemia/reperfusion- (I/R-) induced $\mathrm{AKI}$ [60]. Their results showed that HGF-MSC-treated rats exhibited further improvements in renal cell regeneration, inflammatory responses, and renal functions compared with those of MSC-treated rats [60].

\section{Nuclear Factor E2-Related Factor 2}

Nuclear factor E2-related factor $2(\mathrm{Nrf} 2)$ is an important transcription factor that activates a range of antioxidant responsive element- (ARE-) driven genes, thereby contributing to the modulation of the cellular antioxidant defense system [61]. In recent decades, abundant evidence has suggested that the oxidative stress response plays a critical role in the injury phase of AKI. However, the poor survival of transplanted MSCs in the oxidative stress microenvironment of renal tissues is the principal obstacle faced by the current MSC management strategy for AKI [62]. Interestingly, $\mathrm{Nrf2}(+/+)$ bone marrow stromal cells exhibited increased resistance to oxidative and electrophilic stress compared to Nrf2(-/-) stromal cells [63]. Nrf2-overexpressing MSCs were established by using recombinant adenoviruses and transplanted into rats with AKI induced by cisplatin, and the results demonstrated that the transplantation of Nrf2-MSCs resulted in a superior therapeutic effect on the complications of AKI [64]. Furthermore, Zhaleh et al. demonstrated that plasmid-mediated overexpression of Nrf2 in MSCs downregulated the levels of injury markers and upregulated the levels of repair-induced genes after transplantation in rats suffering from glycerol-induced AKI [65].

\section{Klotho}

Klotho is a membrane-bound protein that was originally identified as a suppressor of aging-related genes. Klotho is emerging as both a pharmaceutical agent and a highly promising biomarker for AKI [66]. Prior administration of adenoviruses harboring the Klotho gene significantly attenuated apoptosis in mice subjected to bilateral renal ischemia [67]. In addition, Klotho is a crucial suppressor of renal fibrosis, and its antifibrotic effect is mediated by the inhibition of Wnt signaling [68]. The available evidence supports the hypothesis that targeted renal delivery of Klotho via MSC transplantation could have a strong reparative effect on AKI. Zhang et al. demonstrated in a mouse model that the administration of Klotho gene-modified bone marrow- derived MSCs more significantly mitigated kidney fibrosis resulting from ischemia/reperfusion injury (IRI) than that of unmodified MSC transplantation [69]. Additionally, the protective effects of bone marrow-derived MSCs on renal IRI were considerably increased by overexpressing the Klotho gene, as determined by TUNEL staining and serum creatinine assessment [70].

\section{Heme Oxygenase-1}

Heme oxygenase-1 (HO-1) is a rate-limiting enzyme that participates in heme breakdown, leading to the production of iron, biliverdin, and carbon monoxide. These degradation byproducts regulate a wide array of vital biological functions that involve anti-inflammation, antioxidation, and cellular protection [71]. Accumulating evidence suggests that HO-1 plays a critical cytoprotective role in different types of kidney disease. Of note, experimental studies have demonstrated that a variety of therapeutic agents for the treatment of AKI exert their protective effects by inducing the generation of HO-1 [72]. However, HO-1-deficient mice were more susceptible to renal function deterioration and tubular injury after cisplatin-induced AKI [73]. HO-1 overexpression by a lentiviral vector greatly improved the survival of MSCs in the context of AKI induced by I/R, which was accompanied by significant improvements in renal function and an improved anti-inflammatory effect [74]. These authors also reported that HO-1-overexpressing MSCs exhibited increased proliferation and improved differentiation abilities in the AKI microenvironment [75].

\section{Other Strategies to Enhance the Therapeutic Efficacy of MSCs}

In addition to genetic manipulation, another strategy which is aimed at enhancing the therapeutic potential of MSCs is to precondition MSCs in vitro. In particular, culturing MSCs under hypoxic conditions in vitro can enhance the secretion of trophic factors and their migratory capacity [76]. Yu et al. demonstrated that hypoxic preconditioning of MSCs resulted in greater improvements in renal function in a rat model of ischemic AKI by alleviating apoptosis and promoting angiogenesis [77]. The efficacy of MSCs is critically affected by their source of origin, number of passages, and delivery route. Adipose-derived MSCs perform better than bone marrow-derived MSCs in terms of stimulating the production of anti-inflammatory factor interleukin-10 (IL-10) by dendritic cells [78], which may bring incremental benefits to AKI. Moreover, pluripotent stem cell-(PSC-) derived MSCs possess better of cell quality with batch-to-batch consistency and higher proliferative potential, exhibiting superior therapeutic benefits for tissue regeneration to BMderived MSCs [79]. Recently, induced pluripotent stem cell(iPSC-) derived MSCs have been applied in steroidresistant acute graft versus host disease and demonstrated good safety and tolerability in clinical trials [80]. iPSCderived MSCs may provide another putative cellular source overcome many limitations of adult MSC used in immune disorder-provoked AK. There are many disadvantages of 
using adult MSC (i.e., BM-MSC) including stem cell senescence. Liang et al. found that rejuvenation of aged MSC via overexpressing Erb-B2 receptor tyrosine kinase 4 (ERBB4) could enhance angiogenesis via PI3K/AKT and MAPK/ERK pathways [81], which may improve the potential efficacy of MSCs in treating AKI. Bustos et al. demonstrated that aged MSCs lacked the anti-inflammatory protective effect compared to their young counterparts, implying young MSCs may display a superior protective role in diseases [82]. The route of MSC administration is commonly systemic transplantation; while only a small proportion of MSCs migrated to injured renal tissue after infusion, most of the cells were trapped in other organs such as lung, spleen, and heart. It is reasonable to assume that local injection may be another approach to enhance the therapeutic efficacy of MSCs.

\section{Concerns regarding Genetically Modified MSC Therapy in AKI}

It would take quite a long time to harvest enough genemodified MSCs due to the relatively complex genetic transfection procedure. Notably, the study performed by Lee et al. showed that the levels of stress- and apoptosis-related genes in MSCs were markedly increased over time [83]. Thus, time is a vital element to be considered when transplanting genetically modified MSCs because older MSCs exhibit weakened protective effects [82]. Little is currently known about the long-term behavior of genetically modified MSCs in vivo and the long-term impacts of genetic manipulation on the characteristics of MSCs, such as the selfrenewal, differentiation, and paracrine properties. Unfortunately, viral vectors and their transgene products may induce innate and adaptive immune responses that limit or even offset the therapeutic potential of gene therapy $[84,85]$. Systematic inflammatory responses triggered by adenoviral vectors negatively affect long-term gene expression and genetic stability [86]. Ideally, MSCs should be administered quickly at the onset of AKI. However, the initial phase of AKI lacks typical symptoms and established biomarkers, making it difficult to apply MSCs as soon as possible. Additionally, AKI is a heterogeneous condition, and so identifying a subgroup of patients who are responsive to MSC-based gene therapy may be extremely crucial in producing the desired efficacy.

\section{Conclusions}

Genetic modification of MSCs represents a promising and effective approach to enhance the therapeutic potential of these cells for AKI treatment. However, among the multiple target genes listed in this review, it remains unknown which gene, after modification in MSCs, will achieve an ideal outcome for the management of AKI. With a more comprehensive understanding of the potential drawbacks and obstacles of genetically modified MSC therapy for AKI, additional efforts will be needed to address these issues prior to the use of MSC-based gene therapy to produce results that can be translated into clinical practice.

\section{Conflicts of Interest}

The authors report no conflict of interest.

\section{Acknowledgments}

This work was supported by the Research Project of Application Foundation of Shanxi Province under Grant $201901 D 211485$.

\section{References}

[1] C. Ronco, R. Bellomo, and J. A. Kellum, "Acute kidney injury," The Lancet, vol. 394, no. 10212, pp. 1949-1964, 2019.

[2] J. A. Kellum and J. R. Prowle, "Paradigms of acute kidney injury in the intensive care setting," Nature Reviews. Nephrology, vol. 14, no. 4, pp. 217-230, 2018.

[3] O. Liangos, R. Wald, J. W. O’Bell, L. Price, B. J. Pereira, and B. L. Jaber, "Epidemiology and outcomes of acute renal failure in hospitalized patients: a national survey," Clinical Journal of the American Society of Nephrology, vol. 1, no. 1, pp. 43-51, 2006.

[4] A. Agarwal, Z. Dong, R. Harris et al., "Acute Dialysis Quality Initiative XIII Working Group. Cellular and molecular mechanisms of AKI," Journal of the American Society of Nephrology, vol. 27, no. 5, pp. 1288-1299, 2016.

[5] H. Rabb, M. D. Griffin, D. B. McKay et al., "Acute Dialysis Quality Initiative Consensus XIII Work Group. Inflammation in AKI: current understanding, key questions, and knowledge gaps," Journal of the American Society of Nephrology, vol. 27, no. 2, pp. 371-379, 2016.

[6] G. R. Kinsey, R. Sharma, and M. D. Okusa, "Regulatory T cells in AKI," Journal of the American Society of Nephrology, vol. 24, no. 11, pp. 1720-1726, 2013.

[7] Y. Ishimoto and R. Inagi, "Mitochondria: a therapeutic target in acute kidney injury," Nephrology, Dialysis, Transplantation, vol. 31, no. 7, pp. 1062-1069, 2016.

[8] S. Kale, A. Karihaloo, P. R. Clark, M. Kashgarian, D. S. Krause, and L. G. Cantley, "Bone marrow stem cells contribute to repair of the ischemically injured renal tubule," The Journal of Clinical Investigation, vol. 112, no. 1, pp. 42-49, 2003.

[9] M. Morigi, M. Introna, B. Imberti et al., "Human bone marrow mesenchymal stem cells accelerate recovery of acute renal injury and prolong survival in mice," Stem Cells, vol. 26, no. 8, pp. 2075-2082, 2008.

[10] M. B. Herrera, B. Bussolati, S. Bruno et al., "Exogenous mesenchymal stem cells localize to the kidney by means of CD44 following acute tubular injury," Kidney International, vol. 72, no. 4, pp. 430-441, 2007.

[11] A. J. Friedenstein, R. K. Chailakhjan, and K. S. Lalykina, "The development of fibroblast colonies in monolayer cultures of guinea-pig bone marrow and spleen cells," Cell and Tissue Kinetics, vol. 3, no. 4, pp. 393-403, 1970.

[12] D. J. Prockop, "Marrow stromal cells as stem cells for nonhematopoietic tissues," Science, vol. 276, no. 5309, pp. 71-74, 1997.

[13] M. Dominici, K. Le Blanc, I. Mueller et al., "Minimal criteria for defining multipotent mesenchymal stromal cells. The International Society for Cellular Therapy position statement," Cytotherapy, vol. 8, no. 4, pp. 315-317, 2006. 
[14] J. Galipeau, M. Krampera, J. Barrett et al., "International Society for Cellular Therapy perspective on immune functional assays for mesenchymal stromal cells as potency release criterion for advanced phase clinical trials," Cytotherapy, vol. 18, no. 2, pp. 151-159, 2016.

[15] Y. Zhang, X. Liang, Q. Lian, and H.-F. Tse, "Perspective and challenges of mesenchymal stem cells for cardiovascular regeneration," Expert Review of Cardiovascular Therapy, vol. 11, no. 4, pp. 505-517, 2014.

[16] F. Tögel, Z. Hu, K. Weiss, J. Isaac, C. Lange, and C. Westenfelder, "Administered mesenchymal stem cells protect against ischemic acute renal failure through differentiationindependent mechanisms," American Journal of Physiology. Renal Physiology, vol. 289, no. 1, pp. F31-F42, 2005.

[17] S. Bruno, C. Grange, M. C. Deregibus et al., "Mesenchymal stem cell-derived microvesicles protect against acute tubular injury," Journal of the American Society of Nephrology, vol. 20, no. 5, pp. 1053-1067, 2009.

[18] J. Sun, J. Zhang, J. Tian et al., "Mitochondria in sepsis-induced AKI," Journal of the American Society of Nephrology, vol. 30, no. 7, pp. 1151-1161, 2019.

[19] S. E. Lee, J. E. Jang, H. S. Kim et al., "Mesenchymal stem cells prevent the progression of diabetic nephropathy by improving mitochondrial function in tubular epithelial cells," Experimental \& Molecular Medicine, vol. 51, no. 7, p. 77, 2019.

[20] A. Bonavia and K. Singbartl, "A review of the role of immune cells in acute kidney injury," Pediatric Nephrology, vol. 33, no. 10, pp. 1629-1639, 2018.

[21] J. Y. Ye, G. C. F. Chan, L. Qiao et al., "Platelet-derived growth factor enhances platelet recovery in a murine model of radiation-induced thrombocytopenia and reduces apoptosis in megakaryocytes via its receptors and the PI3-k/Akt pathway," Haematologica, vol. 95, no. 10, pp. 1745-1753, 2010.

[22] K. Singbartl, C. L. Formeck, and J. A. Kellum, "Kidneyimmune system crosstalk in AKI," Seminars in Nephrology, vol. 39, no. 1, pp. 96-106, 2019.

[23] P. Semedo, C. G. Palasio, C. D. Oliveira et al., "Early modulation of inflammation by mesenchymal stem cell after acute kidney injury," International Immunopharmacology, vol. 9, no. 6, pp. 677-682, 2009.

[24] J. Hu, L. Zhang, N. Wang et al., "Mesenchymal stem cells attenuate ischemic acute kidney injury by inducing regulatory T cells through splenocyte interactions," Kidney International, vol. 84, no. 3, pp. 521-531, 2013.

[25] Y. Geng, L. Zhang, B. Fu et al., "Mesenchymal stem cells ameliorate rhabdomyolysis-induced acute kidney injury via the activation of M2 macrophages," Stem Cell Research \& Therapy, vol. 5, no. 3, p. 80, 2014.

[26] F. E. Togel and C. Westenfelder, "Mesenchymal stem cells: a new therapeutic tool for AKI," Nature Reviews. Nephrology, vol. 6, no. 3, pp. 179-183, 2010.

[27] M. Swaminathan, M. Stafford-Smith, G. M. Chertow et al., "Allogeneic mesenchymal stem cells for treatment of AKI after cardiac surgery," Journal of the American Society of Nephrology, vol. 29, no. 1, pp. 260-267, 2017.

[28] J. Wagner, T. Kean, R. Young, J. E. Dennis, and A. I. Caplan, "Optimizing mesenchymal stem cell-based therapeutics," Current Opinion in Biotechnology, vol. 20, no. 5, pp. 531-536, 2009.

[29] T. J. Myers, F. Granero-Molto, L. Longobardi, T. Li, Y. Yan, and A. Spagnoli, "Mesenchymal stem cells at the intersection of cell and gene therapy," Expert Opinion on Biological Ther$a p y$, vol. 10, no. 12, pp. 1663-1679, 2010.

[30] C. D. Porada and G. Almeida-Porada, "Mesenchymal stem cells as therapeutics and vehicles for gene and drug delivery," Advanced Drug Delivery Reviews, vol. 62, no. 12, pp. 11561166, 2010.

[31] J. D. Mosca, J. K. Hendricks, D. Buyaner et al., "Mesenchymal stem cells as vehicles for gene delivery," Clinical Orthopaedics and Related Research, vol. 379, pp. S71-S90, 2000.

[32] H. Tsuda, T. Wada, Y. Ito et al., "Efficient BMP2 gene transfer and bone formation of mesenchymal stem cells by a fibermutant adenoviral vector," Molecular Therapy, vol. 7, no. 3, pp. 354-365, 2003.

[33] M. F. Naso, B. Tomkowicz, W. L. Perry, and W. R. Strohl, "Adeno-associated virus (AAV) as a vector for gene therapy," BioDrugs, vol. 31, no. 4, pp. 317-334, 2017.

[34] S. Nayak and R. W. Herzog, "Progress and prospects: immune responses to viral vectors," Gene Therapy, vol. 17, no. 3, pp. 295-304, 2010

[35] J. L. Santos, D. Pandita, J. Rodrigues, A. P. Pego, P. L. Granja, and H. Tomas, "Non-viral gene delivery to mesenchymal stem cells: methods, strategies and application in bone tissue engineering and regeneration," Current Gene Therapy, vol. 11, no. 1, pp. 46-57, 2011.

[36] P. J. Canatella and M. R. Prausnitz, "Prediction and optimization of gene transfection and drug delivery by electroporation," Gene Therapy, vol. 8, no. 19, pp. 1464-1469, 2001.

[37] Z. Pu, X. You, Q. Xu et al., "Protein expression of mesenchymal stem cells after transfection of pcDNA3.1--hVEGF165by ultrasound-targeted microbubble destruction," Journal of Biomedicine and Biotechnology, vol. 2011, Article ID 839653, 4 pages, 2011.

[38] W. Wang, X. Xu, Z. Li, A. Lendlein, and N. Ma, "Genetic engineering of mesenchymal stem cells by non-viral gene delivery," Clinical Hemorheology and Microcirculation, vol. 58, no. 1, pp. 19-48, 2014.

[39] L. A. Marquez-Curtis and A. Janowska-Wieczorek, "Enhancing the migration ability of mesenchymal stromal cells by targeting the SDF-1/CXCR4 axis," BioMed Research International, vol. 2013, Article ID 561098, 15 pages, 2013.

[40] J. X. Yang, N. Zhang, H. W. Wang, P. Gao, Q. P. Yang, and Q. P. Wen, "CXCR4 receptor overexpression in mesenchymal stem cells facilitates treatment of acute lung injury in rats," The Journal of Biological Chemistry, vol. 290, no. 4, pp. 1994-2006, 2015.

[41] N. Liu, A. Patzak, and J. Zhang, "CXCR4-overexpressing bone marrow-derived mesenchymal stem cells improve repair of acute kidney injury," American Journal of Physiology. Renal Physiology, vol. 305, no. 7, pp. F1064-F1073, 2013.

[42] K. Maiese, F. Li, and Z. Z. Chong, "New avenues of exploration for erythropoietin," JAMA, vol. 293, no. 1, pp. 90-95, 2005.

[43] C. Westenfelder, "Unexpected renal actions of erythropoietin," Experimental Nephrology, vol. 10, no. 5-6, pp. 294-298, 2002.

[44] D. W. Johnson, B. Pat, D. A. Vesey, Z. Guan, Z. Endre, and G. C. Gobe, "Delayed administration of darbepoetin or erythropoietin protects against ischemic acute renal injury and failure," Kidney International, vol. 69, no. 10, pp. 1806-1813, 2006.

[45] N. Eliopoulos, J. Zhao, K. Forner, E. Birman, Y. K. Young, and M. Bouchentouf, "Erythropoietin gene-enhanced marrow mesenchymal stromal cells decrease cisplatin-induced kidney 
injury and improve survival of allogeneic mice," Molecular Therapy, vol. 19, no. 11, pp. 2072-2083, 2011.

[46] J. A. Clements, N. M. Willemsen, S. A. Myers, and Y. Dong, "The tissue kallikrein family of serine proteases: functional roles in human disease and potential as clinical biomarkers," Critical Reviews in Clinical Laboratory Sciences, vol. 41, no. 3, pp. 265-312, 2008.

[47] A. Pizard, C. Richer, N. Bouby et al., "Genetic deficiency in tissue kallikrein activity in mouse and man: effect on arteries, heart and kidney," Biological Chemistry, vol. 389, no. 6, pp. 701-706, 2008.

[48] J. J. Zhang, G. Bledsoe, K. Kato, L. Chao, and J. Chao, “Tissue kallikrein attenuates salt-induced renal fibrosis by inhibition of oxidative stress," Kidney International, vol. 66, no. 2, pp. 722732, 2004.

[49] M. Hagiwara, B. Shen, L. Chao, and J. Chao, "Kallikrein-modified mesenchymal stem cell implantation provides enhanced protection against acute ischemic kidney injury by inhibiting apoptosis and inflammation," Human Gene Therapy, vol. 19, no. 8, pp. 807-819, 2008.

[50] A. P. Laddha and Y. A. Kulkarni, "VEGF and FGF-2: promising targets for the treatment of respiratory disorders," Respiratory Medicine, vol. 156, pp. 33-46, 2019.

[51] E. Guise and A. R. Chade, "VEGF therapy for the kidney: emerging strategies," American Journal of Physiology. Renal Physiology, vol. 315, no. 4, pp. F747-F751, 2018.

[52] F. Tögel, P. Zhang, Z. Hu, and C. Westenfelder, "VEGF is a mediator of the renoprotective effects of multipotent marrow stromal cells in acute kidney injury," Journal of Cellular and Molecular Medicine, vol. 13, no. 8B, pp. 2109-2114, 2009.

[53] F. Tögel, A. Cohen, P. Zhang, Y. Yang, Z. Hu, and C. Westenfelder, "Autologous and allogeneic marrow stromal cells are safe and effective for the treatment of acute kidney injury," Stem Cells and Development, vol. 18, no. 3, pp. 475486, 2009.

[54] L. Yuan, M. J. Wu, H. Y. Sun et al., "VEGF-modified human embryonic mesenchymal stem cell implantation enhances protection against cisplatin-induced acute kidney injury," American Journal of Physiology. Renal Physiology, vol. 300, no. 1, pp. F207-F218, 2011.

[55] P. Boros and C. M. Miller, "Hepatocyte growth factor: a multifunctional cytokine," The Lancet, vol. 345, no. 8945, pp. 293-295, 1995.

[56] S. B. Miller, D. R. Martin, J. Kissane, and M. R. Hammerman, "Hepatocyte growth factor accelerates recovery from acute ischemic renal injury in rats," American Journal of Physiology-Renal Physiology, vol. 266, 1, Part 2, pp. F129F134, 1994.

[57] K. Kawaida, K. Matsumoto, H. Shimazu, and T. Nakamura, "Hepatocyte growth factor prevents acute renal failure and accelerates renal regeneration in mice," Proceedings of the National Academy of Sciences of the United States of America, vol. 91, no. 10, pp. 4357-4361, 1994.

[58] K. Matsumoto and T. Nakamura, "Hepatocyte growth factor: renotropic role and potential therapeutics for renal diseases," Kidney International, vol. 59, no. 6, pp. 2023-2038, 2001.

[59] G. A. Vargas, A. Hoeflich, and P. M. Jehle, "Hepatocyte growth factor in renal failure: promise and reality," Kidney International, vol. 57, no. 4, pp. 1426-1436, 2000.

[60] Y. Chen, H. Qian, W. Zhu et al., "Hepatocyte growth factor modification promotes the amelioration effects of human umbilical cord mesenchymal stem cells on rat acute kidney injury," Stem Cells and Development, vol. 20, no. 1, pp. 103113, 2011.

[61] J. M. Lee and J. A. Johnson, "An important role of Nrf2-ARE pathway in the cellular defense mechanism," Journal of Biochemistry and Molecular Biology, vol. 37, no. 2, pp. 139-143, 2004.

[62] A. J. Peired, A. Sisti, and P. Romagnani, "Mesenchymal stem cell-based therapy for kidney disease: a review of clinical evidence," Stem Cells International, vol. 2016, Article ID 4798639, 22 pages, 2016.

[63] H. Zhu, L. Zhang, K. Itoh et al., "Nrf2 controls bone marrow stromal cell susceptibility to oxidative and electrophilic stress," Free Radical Biology \& Medicine, vol. 41, no. 1, pp. 132-143, 2006.

[64] M. Mohammadzadeh-Vardin, R. M. Habibi, and A. JahanianNajafabadi, "Adenovirus-mediated over-expression of Nrf2 within mesenchymal stem cells (MSCs) protected rats against acute kidney injury," Advanced Pharmaceutical Bulletin, vol. 5, no. 2, pp. 201-208, 2015.

[65] F. Zhaleh, F. Amiri, M. Mohammadzadeh-Vardin et al., "Nuclear factor erythroid-2 related factor 2 overexpressed mesenchymal stem cells transplantation, improves renal function, decreases injuries markers and increases repair markers in glycerol-induced acute kidney injury rats," Iranian Journal of Basic Medical Sciences, vol. 19, no. 3, pp. 323-329, 2016.

[66] M. C. Hu and O. W. Moe, "Klotho as a potential biomarker and therapy for acute kidney injury," Nature Reviews. Nephrology, vol. 8, no. 7, pp. 423-429, 2012.

[67] H. Sugiura, T. Yoshida, M. Mitobe et al., "Klotho reduces apoptosis in experimental ischaemic acute kidney injury via HSP70," Nephrology, Dialysis, Transplantation, vol. 25, no. 1, pp. 60-68, 2009.

[68] M. Satoh, H. Nagasu, Y. Morita, T. P. Yamaguchi, Y. S. Kanwar, and N. Kashihara, "Klotho protects against mouse renal fibrosis by inhibiting Wnt signaling," American Journal of Physiology. Renal Physiology, vol. 303, no. 12, pp. F1641F1651, 2012.

[69] F. Zhang, X. Wan, Y. Z. Cao, D. Sun, and C. C. Cao, "Klotho gene-modified BMSCs showed elevated antifibrotic effects by inhibiting the Wnt/ $\beta$-catenin pathway in kidneys after acute injury," Cell Biology International, vol. 42, no. 12, pp. 1670$1679,2018$.

[70] L. B. Xie, X. Chen, B. Chen, X. D. Wang, R. Jiang, and Y. P. Lu, "Protective effect of bone marrow mesenchymal stem cells modified with klotho on renal ischemia-reperfusion injury," Renal Failure, vol. 41, no. 1, pp. 175-182, 2019.

[71] S. Bolisetty, A. Zarjou, and A. Agarwal, "Heme oxygenase 1 as a therapeutic target in acute kidney injury," American Journal of Kidney Diseases, vol. 69, no. 4, pp. 531-545, 2017.

[72] T. Jarmi and A. Agarwal, "Heme oxygenase and renal disease," Current Hypertension Reports, vol. 11, no. 1, pp. 56-62, 2009.

[73] A. Agarwal and H. S. Nick, "Renal response to tissue injury: lessons from heme oxygenase-1 gene ablation and expression," Journal of the American Society of Nephrology, vol. 11, no. 5, pp. 965-973, 2000.

[74] N. Liu, H. Wang, G. Han, J. Tian, W. Hu, and J. Zhang, “Alleviation of apoptosis of bone marrow-derived mesenchymal stem cells in the acute injured kidney by heme oxygenase- 1 gene modification," The International Journal of Biochemistry \& Cell Biology, vol. 69, pp. 85-94, 2015. 
[75] N. Liu, H. Wang, G. Han, J. Cheng, W. Hu, and J. Zhang, "Enhanced proliferation and differentiation of HO-1 genemodified bone marrow-derived mesenchymal stem cells in the acute injured kidney," International Journal of Molecular Medicine, vol. 42, no. 2, pp. 946-956, 2018.

[76] I. Rosová, M. Dao, B. Capoccia, D. Link, and J. A. Nolta, "Hypoxic preconditioning results in increased motility and improved therapeutic potential of human mesenchymal stem cells," Stem Cells, vol. 26, no. 8, pp. 2173-2182, 2008.

[77] X. Yu, C. Lu, H. Liu et al., "Hypoxic preconditioning with cobalt of bone marrow mesenchymal stem cells improves cell migration and enhances therapy for treatment of ischemic acute kidney injury," PLoS One, vol. 8, no. 5, article e62703, 2013.

[78] E. Ivanova-Todorova, I. Bochev, M. Mourdjeva et al., "Adipose tissue-derived mesenchymal stem cells are more potent suppressors of dendritic cells differentiation compared to bone marrow-derived mesenchymal stem cells," Immunology Letters, vol. 126, no. 1-2, pp. 37-42, 2009.

[79] J. Zhang, Y.-C. Chan, J. C.-Y. Ho, C.-W. Siu, Q. Lian, and H.F. Tse, "Regulation of cell proliferation of human induced pluripotent stem cell-derived mesenchymal stem cells via ether-àgo-go 1 (hEAG1) potassium channel," American Journal of Physiology. Cell Physiology, vol. 303, no. 2, pp. C115-C125, 2012.

[80] A. J. C. Bloor, A. Patel, J. E. Griffin et al., "Production, safety and efficacy of iPSC-derived mesenchymal stromal cells in acute steroid-resistant graft versus host disease: a phase I, multicenter, open-label, dose-escalation study," Nature Medicine, vol. 26, no. 11, pp. 1720-1725, 2020.

[81] X. Liang, Y. Ding, F. Lin et al., "Overexpression of ERBB4 rejuvenates aged mesenchymal stem cells and enhances angiogenesis via PI3K/AKT and MAPK/ERK pathways," The FASEB Journal, vol. 33, no. 3, pp. 4559-4570, 2018.

[82] M. L. Bustos, L. Huleihel, M. G. Kapetanaki et al., “Aging mesenchymal stem cells fail to protect because of impaired migration and antiinflammatory response," American Journal of Respiratory and Critical Care Medicine, vol. 189, no. 7, pp. 787-798, 2014.

[83] K. A. Lee, W. Shim, M. J. Paik et al., "Analysis of changes in the viability and gene expression profiles of human mesenchymal stromal cells over time," Cytotherapy, vol. 11, no. 6, pp. 688697, 2009.

[84] S. Hareendran, B. Balakrishnan, D. Sen, S. Kumar, A. Srivastava, and G. R. Jayandharan, "Adeno-associated virus (AAV) vectors in gene therapy: immune challenges and strategies to circumvent them," Reviews in Medical Virology, vol. 23, no. 6, pp. 399-413, 2013.

[85] K. Jooss and N. Chirmule, "Immunity to adenovirus and adeno-associated viral vectors: implications for gene therapy," Gene Therapy, vol. 10, no. 11, pp. 955-963, 2003.

[86] A. K. Zaiss and D. A. Muruve, "Immunity to adeno-associated virus vectors in animals and humans: a continued challenge," Gene Therapy, vol. 15, no. 11, pp. 808-816, 2008. 